\title{
Effects of Hogweed (Heracleum persicum) Powder, Flavophospholipol, and Probiotics as Feed Supplements on the Performance, Carcass and Blood Characteristics, Intestinal Microflora, and Immune Response in Broilers
}

\author{
Faramin Javandel ${ }^{1}$, Mehran Nosrati $^{1}$, René van den Hoven ${ }^{2}$, Alireza Seidavi ${ }^{1}$, \\ Vito Laudadio ${ }^{3}$ and Vincenzo Tufarelli ${ }^{3}$ \\ ${ }^{1}$ Department of Animal Science, Rasht Branch, Islamic Azad University, Rasht, Iran \\ ${ }^{2}$ University of Veterinary Medicine, Vienna. Austria \\ ${ }^{3}$ Section of Veterinary Science and Animal Production, Department of DETO, \\ University of Bari 'Aldo Moro', Valenzano, Bari, Italy
}

\begin{abstract}
The effect of different levels of hogweed powder (HP; Heracleum persicum), flavophospholipol (antibiotic), and probiotics in diet on the performance, carcass quality, blood biochemical parameters, immunity, and intestinal flora of broiler chickens was investigated. In total, 270-day-old male broilers were randomly assigned to six treatment groups as follows: control basal-diet and diet supplemented with flavophospholipol, probiotics, or $0.25,0.5$, and $0.75 \%$ HP. Birds in each group were divided into three subgroups with 15 chicks each. Results indicated that the treatment groups did not vary with respect to feed intake (FI), whereas those supplemented with the antibiotic or $0.5 \%$ HP showed significantly higher body weight gain (BWG) and improved feed conversion ratio (FCR). Carcass characteristics did not vary among treatments, with the exception of abdominal fat percentage, which was the lowest in broilers fed $0.5 \%$ and $0.75 \%$ HP. Supplementation of $0.5 \%$ and $0.75 \%$ HP decreased plasma cholesterol and triglyceride levels. Furthermore, dietary HP significantly reduced serum low density lipoprotein (LDL) levels compared to that in the other groups. Antibody titers against Newcastle disease vaccine were not markedly affected by the treatments, whereas titers against avian influenza vaccine were significantly higher in probiotic- and $0.75 \%$ HPsupplemented groups. Antibody production against sheep red blood cells (SRBC) and IgM and IgG levels were not significantly different among groups. The ileum Lactobacillus counts in broilers fed $0.5 \%$ or $0.75 \%$ HP were significantly higher than those in the other treatment groups, whereas Escherichia coli counts in all treatments were significantly lower than that in the control. Therefore, our observations indicated that HP positively affected the gut microbiota and enhanced feed digestion. In conclusion, supplementation of $0.50-0.75 \% \mathrm{HP}$ in broiler diet during the entire rearing period improved BWG and decreased abdominal fat deposition.
\end{abstract}

Key words: blood, broiler, Heracleum persicum, immune system, intestinal microflora, probiotics

J. Poult. Sci., 56: 262-269, 2019

\section{Introduction}

Currently, one of the major concerns regarding the consumption of commercially manufactured food is the presence of excess antibiotics and other medical products, especially

Received: August 1, 2018, Accepted: September 21, 2018

Released Online Advance Publication: April 25, 2019

Correspondence: Dr. Vincenzo Tufarelli, Section of Veterinary Science and Animal Production, Department of DETO, University of Bari 'Aldo Moro', Valenzano 70010, Bari, Italy. (E-mail: vincenzo.tufarelli@uniba.it) The Journal of Poultry Science is an Open Access journal distributed under the Creative Commons Attribution-NonCommercial-ShareAlike 4.0 International License. To view the details of this license, please visit (https:// creativecommons.org/licenses/by-nc-sa/4.0/). in poultry items, as this may lead to the development of antibiotic-resistant bacteria and transmission of antibiotic residues into the human food chain (Sanjyal and Sapkota 2011; Dhama et al., 2015). Spices, plant extracts, and various phytobiotics derived from the leaves, roots, tubers, or fruits of herbs have shown excellent growth enhancement in poultry (Wallace et al., 2010; Khan et al., 2012a; Dhama et al., 2015). This may be due to the synergistic action of various active molecules and higher feed utilization efficiency, resulting in enhanced productive performance (Hashemi and Davoodi, 2010; Khan et al., 2012b).

Heracleum persicum (HP) (family: Apiaceae), commonly known as Persian hogweed or golpar, is a flowering plant native to Iran, the seeds of which are used as spice in Persian 
cooking and in traditional and folk medicine (Hasani et al., 2016). Hogweed contains many secondary substances with antioxidant, anticonvulsive, antibiotic, antifungal, and immunestimulatory activity (Nazemi et al., 2005; Sayyah et al., 2005; Shahrani et al., 2006; Asgarpanah et al., 2012). The chemical composition of different parts of hogweed has been investigated and results indicate the presence of six furanocoumarins and flavonoids in the fruits, leaves, flowers, and roots (Sefidkon et al., 2004; Hajhashemi et al., 2014). Previous studies have shown that certain furanocoumarins isolated from hogweed possess antioxidant property against lipid peroxidation (Souri et al., 2004), as well as lipid lowering activity (Phuwapraisirisan et al., 2006). Thus, addition of hogweed leaf powder to broiler diet may improve gut microbiota function and consequently bird growth and performance.

Currently, studies on the productive performance of broilers supplemented with hogweed are limited (Kheiri et al., 2014), although the effects of dietary probiotics (Balevi et al., 2001; Torres-Rodriguez et al., 2005; Jahromi et al., 2016; Seidavi et al., 2017; Tufarelli et al., 2017) and flavophospholipol antibiotics have been extensively studied (Shamsi et al., 2015a, b). Therefore, the objectives of this study were to compare the effects of different amounts of hogweed leaf powder, along with probiotics and flavophospholipol antibiotics, on the performance, carcass quality, blood biochemical parameters, immunity, and intestinal flora of broiler chicks.

\section{Materials and Methods}

All procedures used in the study were approved by the institution's Ethic Committee, and care was taken to minimize the number of animals used.

\section{Animals and Dietary Treatments}

In total, 270-day-old male Ross 308 chicks (Aviagen, Newbridge, Scotland, UK) were randomly assigned to one of six treatment groups while considering that the mean group body weights were similar in each group at the beginning of the experiment. Each group contained 45 birds, and three replicates were made with 15 birds each per group. The study lasted 42 days. Birds were fed isocaloric and isonitrogenous diets, and the ingredients, as well as the calculated nutrient composition, of diets used during starter (1-21 days of age) and finisher (22-42 days of age) periods are shown in Table 1. Nutritional requirements were based on the standard recommendations of the chick's producer (Ross Manual).

The experimental dietary treatments were based on different amounts of hogweed powder, probiotics (PrimaLac), or flavomycin (flavophospholipol antibiotic) as follows:

treatment 1: control (basal-diet); treatment 2: basal-diet supplemented with flavophospholipol antibiotics $(0.525 \mathrm{~g} / \mathrm{kg})$; treatment 3: basal-diet supplemented with probiotics $(0.900$ $\mathrm{g} / \mathrm{kg}$ from $1 \mathrm{st}$ to 14 th days of age, $0.454 \mathrm{~g} / \mathrm{kg}$ from 15 th to 28 th days of age, $0.225 \mathrm{~g} / \mathrm{kg}$ from 29 th to 42 nd days of age) from 1 st to 42 nd days of age; treatment 4 : basal-diet supple-

Table 1. Ingredients and nutritional composition of diets

\begin{tabular}{lcc}
\hline \multicolumn{1}{c}{ Ingredients $(\%)$} & $1-21$ days of age & 22-42 days of age \\
\hline Corn & 56.9 & 58.7 \\
Soybean meal (43\% CP) & 33.1 & 30.0 \\
Fish meal & 3.4 & 3.5 \\
Soybean oil & 2.0 & 3.5 \\
Dicalcium phosphate & 1.55 & 1.55 \\
Oyster shell & 1.03 & 1.18 \\
DL-methionine & 0.01 & 0.01 \\
Vitamin premix* & 0.5 & 0.5 \\
Mineral premix** & 0.5 & 0.5 \\
Salt & 0.26 & 0.26 \\
Sand & 0.75 & 0.75 \\
Nutritional composition & & \\
ME (kcal/kg) & 2,910 & 3,030 \\
Crude protein (\%) & 20.1 & 19.0 \\
Crude fat (\%) & 4.6 & 6.14 \\
Calcium (\%) & 0.95 & 0.9 \\
Total phosphorus (\%) & 1.23 & 1.06 \\
Available phosphorus (\%) & 0.45 & $0 / 36$ \\
Methionine $(\%)$ & 0.5 & 0.38 \\
Lysine (\%) & 1.01 & 1.00 \\
Methionine + Cysteine (\%) & 0.83 & 0.71 \\
\hline
\end{tabular}

*Vitamin A, 360,0000 IU; D3, 800,000 IU; vitamin E, 7,200 IU; vitamin B1, 710 mg; vitamin B2, 2,640 mg; vitamin B6, 1,176 mg; vitamin B9, $400 \mathrm{mg}$; vitamin B12, $6 \mathrm{mg}$; vitamin K3, $800 \mathrm{mg}$; pantothenic acid, 3,920 mg; biotin, $40 \mathrm{mg}$; niacin, $12,000 \mathrm{mg}$; choline chloride, 200,000 mg. ** Mn, 40,000 mg; Fe, 20,000 mg; Zn, 33,900 mg; Cu, 4,000 mg; I, $400 \mathrm{mg}$, and Se, $80 \mathrm{mg}$. 
Table 2. Bacterial content of probiotics used

\begin{tabular}{lcc}
\hline \hline \multicolumn{1}{c}{ Bacteria } & $\mathrm{CFU} / \mathrm{g}$ & $\mathrm{pH}$ \\
\hline Lactobacillus acidophilus & $2.5 \times 10^{7}$ & $5.5-7.0$ \\
Lactobacillus casei & $2.5 \times 10^{7}$ & $4.0-9.0$ \\
Enterococcus faecium & $2.5 \times 10^{7}$ & $4.0-9.0$ \\
Bifidobacterium thermophilum & $2.5 \times 10^{7}$ & $4.0-9.0$ \\
\hline
\end{tabular}

mented with $0.25 \% \mathrm{HP}$; treatment 5 : basal-diet supplemented with $0.50 \% \mathrm{HP}$; treatment 6 : basal-diet supplemented with $0.75 \%$ HP.

\section{Feed Supplements}

The probiotic (PrimaLac, Star-Labs/Forage Research Inc. Clarksdale, MS, USA) was a lyophilized mix containing 2.5 $\times 10^{7} \mathrm{CFU} / \mathrm{g}$ Lactobacillus casei, Lactobacillus acidophilus, Bifidobacterium thermophilum, and Enterococcus faecium (Table 2). The flavophospholipol antibiotic (Flavomycin-4; HuvePharma Inc., Peachtree City, GA, USA) contained $6.8 \mathrm{~g}$ bambermycin per $\mathrm{kg}$ of the premix. Hogweed powder was purchased from a local market.

\section{Housing}

The birds were housed in 18 pens in a broiler rearing facility. Prior to the experiment, the facility was carefully cleaned, including all drinkers and feeders, and was subsequently disinfected (Aqua $\mathrm{GPC}^{\circledR} 10$ ). All drinkers and feeders were immersed in a $20 \%$ benzalkonium chloride solution and the facility was left to dry for two days. Thereafter, the nonflammable parts were ignited, including the floor and metal walls of the pens. The walls were subsequently sprayed with water and lime. Ventilation was turned on to optimize the climate $24 \mathrm{~h}$ before the broilers were brought in. The facility was equipped with eight ventilators and two strong ventilators. A heater was used, and the temperature program was set according to the instructions for Ross 308 broilers (infoworldwide@aviagen.com). Air humidity was maintained at $55-65 \%$ in the early growing period by spraying water on the floor. Twenty-Watt lamps were installed at $2.2 \mathrm{~m}$ above the floor, and the light was kept on for $23 \mathrm{~h}$ daily. The birds were vaccinated against infectious bronchitis (1- and 18-day-old), Newcastle disease (1and 18-day-old), avian influenza (1-day-old) and Gumboro disease (14- and 24-day-old).

\section{Evaluated Parameters}

The feed intake (FI) and body weight (BW) were recorded weekly and feed conversion ratio (FCR) was calculated. Two birds per replicate were selected at 42 days of age after $4 \mathrm{~h}$ of fasting. The most representative birds with BWs displaying the mean group weight were carefully selected, sacrificed, and used for measuring carcass yield, and meat and gastrointestinal tract characteristics. The birds were completely pecked using the dry pecking method. The neck, wing tips, gut, and liver were removed, and the empty or edible carcass was weighed. Furthermore, the intestinal segments were measured. Carcass cuts were dissected and weighed.

The birds were fasted for $4 \mathrm{~h}$ prior to blood sampling in the morning. At 42 days of age, $5 \mathrm{~mL}$ venous blood was collected from the wing vein of the selected bird from each replicate. Blood was transferred from the syringe into a tube coated with $10 \mathrm{mg}$ EDTA and centrifuged at $3,000 \mathrm{rpm} \times 20$ min to separate blood cells from the plasma. Plasma was stored at $-20^{\circ} \mathrm{C}$ until further analyses. The plasma cholesterol and triglyceride levels were determined using enzymatic methods (Teif Azmoon Pars Co., Tehran, Iran), and high density lipoprotein (HDL) and LDL cholesterol levels were measured directly using diagnostic kits (Teif Azmoon Pars Co.). Total cholesterol in plasma samples was colorimetrically determined following the procedure of Barham and Trinder (1972). Plasma triglyceride levels were measured using a series of coupled reactions in which triglycerides are hydrolyzed to produce glycerol, which is converted to pyruvate and subsequently to lactate. Decrease in absorbance, measured spectrophotometrically, is proportional to the triglyceride concentration in the sample (Schmid and Forstner, 1986). Glucose oxidase and uric acid-uricase kits (both from Teif Azmoon Pars Co.), based on the oxidaseperoxidase method (Trinder, 1969), were used to measure plasma glucose and uric acid levels. Sera for antibodies against Newcastle disease were sampled on days 28 and 42 . Non-specific humoral immune response was determined based on the response to sheep red blood cells (SRBC). SRBC was injected on days 21 and 35 and sampling was performed on days 28 and 42 .

\section{Microbiota Analysis}

On days 21 and 42, two chicks were selected from each replicate and sacrificed. Cecum contents were collected for microbial culture. De Man, Rogosa, and Sharpe agar (MRS, 1.10660.500) was used to culture lactobacilli, nutrient agar $(1.05450 .0500)$ was used to determine total aerobic bacteria counts, eosin-methylene blue agar (EMB, 1.01347.0500) was used to culture E. coli, and MacConkey agar (105465.0500) was used to culture coliforms. Serial dilutions were prepared for estimating colony forming units (CFU), which were counted after a $72 \mathrm{~h}$ incubation period at $37^{\circ} \mathrm{C}$ using a colony counter.

\section{Statistical Analysis}

Data were analyzed using the general linear model of the SPSS software (1997). The significance level was set at $P<$ 0.05 and differences among main mean effects were assessed using Duncan's multiple range test.

\section{Results and Discussion}

The effects of inclusion of dietary HP, flavophospholipol, and probiotics as feed supplements in broiler diet on bird growth, carcass and blood characteristics, intestinal microflora, and immune response have not been reported. Therefore, the results of this study will be discussed in the context of observations made in other livestock species. Results of the present study are summarized in Tables 3-13. Although the FI of broilers in groups fed $0.50 \%$ and $0.75 \%$ HP tended to be slightly higher, the difference was not significant. In contrast, birds fed antibiotic, probiotic or $0.50 \%$ and $0.75 \%$ HP had significantly higher BWG. Conversely, the BWG in 
Table 3. Effect of dietary treatments on cumulative feed intake (g) of broilers

\begin{tabular}{lccc}
\hline \multicolumn{1}{c}{ Treatments } & Starter period & Finisher period & Total period \\
\hline Control & 973 & 2701 & 3675 \\
Flavophospholipol & 978 & 2690 & 3668 \\
Probiotics & 976 & 2692 & 3667 \\
$0.25 \% \mathrm{HP}$ & 974 & 2694 & 3668 \\
$0.50 \% \mathrm{HP}$ & 980 & 2724 & 3704 \\
$0.75 \% \mathrm{HP}$ & 980 & 2732 & 3711 \\
\hline SEM & 3.0 & 14.1 & 15.0 \\
P-value & 0.157 & 0.235 & 0.166 \\
\hline
\end{tabular}

SEM: Standard error of means.

Table 4. Effect of dietary treatments on body weight (g) of broilers at the different growing stages

\begin{tabular}{lccc}
\hline \hline \multicolumn{1}{c}{ Treatments } & Starter period & Finisher period & Total period \\
\hline Control & $605^{\mathrm{c}}$ & $1342^{\mathrm{c}}$ & $1947^{\mathrm{c}}$ \\
Flavophospholipol & $687^{\mathrm{a}}$ & $1465^{\mathrm{a}}$ & $2152^{\mathrm{a}}$ \\
Probiotics & $671^{\mathrm{b}}$ & $1410^{\mathrm{b}}$ & $2081^{\mathrm{b}}$ \\
$0.25 \% \mathrm{HP}$ & $609^{\mathrm{c}}$ & $1347^{\mathrm{c}}$ & $1956^{\mathrm{c}}$ \\
$0.50 \% \mathrm{HP}$ & $681^{\mathrm{ab}}$ & $1440^{\mathrm{ab}}$ & $2122^{\mathrm{a}}$ \\
$0.75 \% \mathrm{HP}$ & $687^{\mathrm{a}}$ & $1452^{\mathrm{a}}$ & $2139^{\mathrm{a}}$ \\
\hline SEM & 3.0 & 11.0 & 12.0 \\
P-value & 0.001 & 0.001 & 0.001 \\
\hline
\end{tabular}

Means with different subscripts in the same column differ significantly $(P<0.05)$; SEM: Standard error of means.

Table 5. Effect of dietary treatments on feed conversion ratio (g feed/g gain) of broilers

\begin{tabular}{lccc}
\hline \hline \multicolumn{1}{c}{ Treatments } & Starter period & Finisher period & Total period \\
\hline Control & $1.6^{\mathrm{a}}$ & $2.0^{\mathrm{a}}$ & $1.9^{\mathrm{a}}$ \\
Flavophospholipol & $1.4^{\mathrm{c}}$ & $1.8^{\mathrm{c}}$ & $1.7^{\mathrm{c}}$ \\
Probiotics & $1.5^{\mathrm{b}}$ & $1.9^{\mathrm{b}}$ & $1.8^{\mathrm{b}}$ \\
$0.25 \% \mathrm{HP}$ & $1.6^{\mathrm{a}}$ & $2.0^{\mathrm{a}}$ & $1.9^{\mathrm{a}}$ \\
$0.50 \% \mathrm{HP}$ & $1.4^{\mathrm{bc}}$ & $1.9^{\mathrm{bc}}$ & $1.70^{\mathrm{c}}$ \\
$0.75 \% \mathrm{HP}$ & $1.4^{\mathrm{c}}$ & $1.9^{\mathrm{bc}}$ & $1.7^{\mathrm{bc}}$ \\
\hline SEM & 0.01 & 0.01 & 0.01 \\
P-value & 0.001 & 0.001 & 0.001 \\
\hline
\end{tabular}

Means with different subscripts in the same column differ significantly $(P<0.05)$; SEM: Standard error of means.

broilers fed $0.25 \%$ HP was not significantly different from those of birds fed control diet. This suggests that $0.25 \%$ HP is too low to support good growth performance. Compared to other groups, broilers in groups fed antibiotic-, probiotic-, or $0.50 \%$ and $0.75 \%$ HP-supplemented diets showed significantly improved FCR $(P<0.05)$. Thus, supplementation of the basal-diet of broilers with $0.50 \%$ or higher levels of HP, as well as with probiotics or antibiotics, resulted in better and efficient growth. In a recent study, Kheiri et al. (2014) evaluated the performance traits of broilers fed different levels of hogweed extract via drinking water and observed improved response of the treated birds.

For economic utility, the observed better growth must be accompanied by better carcass yield and quality. However, neither the percentage carcass yield nor the percentage of breast muscle and drumsticks differed significantly among the groups, indicating that the weight gain was evenly distributed over the entire body, with the exception of abdominal fat deposition. A small, but significant decrease in abdominal fat percentage was observed in birds fed $0.5 \%$ and 
Table 6. Effect of dietary treatments on relative carcass characteristics and organ yield (\%) of 42-day-old broilers

\begin{tabular}{lccccccc}
\hline \hline \multicolumn{1}{c}{ Treatments } & Carcass & Breast & Thigh & Wing & Liver & Gizzard & Abdominal fat \\
\hline Control & 74 & 28 & 26 & 0.8 & 0.3 & 0.3 & $0.18^{\mathrm{a}}$ \\
Flavophospholipol & 75 & 29 & 27 & 0.8 & 0.4 & 0.3 & $0.17^{\mathrm{b}}$ \\
Probiotics & 75 & 28 & 26 & 0.8 & 0.3 & 0.3 & $0.11^{\mathrm{c}}$ \\
$0.25 \%$ HP & 75 & 28 & 26 & 0.8 & 0.3 & 0.3 & $0.13^{\mathrm{c}}$ \\
$0.50 \%$ HP & 74 & 29 & 26 & 0.8 & 0.3 & 0.3 & $0.11^{\mathrm{d}}$ \\
$0.75 \%$ HP & 75 & 29 & 27 & 0.8 & 0.3 & 0.3 & $0.10^{\mathrm{d}}$ \\
\hline SEM & 0.60 & 0.41 & 0.22 & 0.01 & 0.01 & 0.01 & 0.01 \\
P-value & 0.449 & 0.814 & 0.814 & 0.407 & 0.599 & 0.270 & 0.0001 \\
\hline
\end{tabular}

Means with different subscripts in the same column differ significantly $(P<0.05)$; SEM: Standard error of means.

Table 7. Effect of dietary treatments on organ weight (g) of 42-day-old broilers

\begin{tabular}{lccccc}
\hline \hline \multicolumn{1}{c}{ Treatments } & Pancreas & Hearth & Spleen & Thymus & Bursa Fabricius \\
\hline Control & 5 & 12 & 2 & 4 & 2 \\
Flavophospholipol & 6 & 14 & 2 & 5 & 2 \\
Probiotics & 4 & 16 & 2 & 3 & 2 \\
$0.25 \%$ HP & 4 & 13 & 2 & 5 & 1 \\
$0.50 \%$ HP & 6 & 12 & 2 & 4 & 1 \\
$0.75 \%$ HP & 8 & 11 & 3 & 3 & 1 \\
\hline SEM & 1.2 & 2.2 & 0.6 & 0.8 & 0.4 \\
P-value & 0.345 & 0.774 & 0.647 & 0.400 & 0.409 \\
\hline
\end{tabular}

Table 8. Effect of treatment on organ weight (g) of 42-day-old broilers

\begin{tabular}{lccc}
\hline \hline \multicolumn{1}{c}{ Treatments } & Proventriculus & Small intestine & Large intestine \\
\hline Control & 10 & 72 & 22 \\
Flavophospholipol & 11 & 82 & 23 \\
Probiotics & 10 & 74 & 20 \\
$0.25 \%$ HP & 9 & 81 & 23 \\
$0.50 \%$ HP & 8 & 93 & 23 \\
$0.75 \%$ HP & 9 & 89 & 27 \\
\hline SEM & 1.0 & 8.0 & 3.0 \\
P-value & 0.685 & 0.468 & 0.481 \\
\hline
\end{tabular}

SEM: Standard error of means.

$0.75 \%$ HP powder. Low fat deposition may be associated with the expression of markers of fat metabolism in blood. Serum HDL levels did not vary significantly among the treatments. However, dietary supplementation with $0.5 \%$ and $0.75 \%$ HP decreased plasma cholesterol and triglyceride levels. Furthermore, compared to the non-HP treated groups, groups with different amounts of HP supplementation showed significantly lower serum LDL levels. Thus, these markers confirmed that $0.5 \%$ and $0.75 \% \mathrm{HP}$ powder reduced fat deposition in broiler carcass. In agreement with our results, Hajhashemi et al. (2014) reported that the essential oil of hogweed increases HDL-cholesterol and decreases LDL-cholesterol levels in rabbits. However, the mechanism via which the hypolipidemic activity of hogweed reduces LDL is still not understood. Possibly, it may reduce LDL by inhibiting intestinal absorption of cholesterol via a mechanism similar to that of ezetimibe (Sweeney and Johnson 2007; Hajhashemi et al., 2014). Furthermore, 0.5\% and $0.75 \%$ HP powder significantly reduced plasma glucose levels, indicating optimal pancreas function in concert with muscle uptake.

Antibody titers against Newcastle disease vaccine were not markedly affected by the treatments, whereas antibody titer against the avian influenza vaccine were significantly higher in the probiotic- and $0.75 \% \mathrm{HP}$-supplemented groups than in other groups $(P<0.05)$. However, since antibody 
Table 9. Effect of treatment on serum biochemical parameters at 42 days of age

\begin{tabular}{lccccc}
\hline \hline \multicolumn{1}{c}{ Treatments } & Total protein $(\mathrm{g} / \mathrm{d} l)$ & Albumin $(\mathrm{g} / \mathrm{d} l)$ & Glucose $(\mathrm{mg} / \mathrm{d} l)$ & Cholesterol $(\mathrm{mg} / \mathrm{d} l)$ & Triglyceride $(\mathrm{mg} / \mathrm{d} l)$ \\
\hline Control & 4.4 & 1.7 & 207 & $155^{\mathrm{a}}$ & $70^{\mathrm{a}}$ \\
Flavophospholipol & 4.5 & 2.2 & 209 & $157^{\mathrm{a}}$ & $72^{\mathrm{a}}$ \\
Probiotics & 4.6 & 2.3 & 202 & $141^{\mathrm{ab}}$ & $57^{\mathrm{ab}}$ \\
$0.25 \%$ HP & 3.6 & 1.7 & 208 & $136^{\mathrm{ab}}$ & $51^{\mathrm{ab}}$ \\
$0.50 \%$ HP & 4.0 & 1.9 & 212 & $128^{\mathrm{b}}$ & $39^{\mathrm{a}}$ \\
$0.75 \%$ HP & 4.7 & 1.7 & 214 & $129^{\mathrm{b}}$ & $35^{\mathrm{b}}$ \\
\hline SEM & 0.31 & 0.32 & 13.01 & 7.04 & 7.07 \\
P-value & 0.295 & 0.619 & 0.991 & 0.061 & 0.009 \\
\hline
\end{tabular}

Means with different subscripts in the same column differ significantly $(P<0.05)$; SEM: Standard error of means.

Table 10. Effect of treatment on serum biochemical parameters at 42 days of age

\begin{tabular}{lcccc}
\hline \hline \multicolumn{1}{c}{ Treatments } & HDL & LDL & Uric acid (mg/d $l)$ & Alkaline phosphatase $(\mathrm{mg} / \mathrm{d} l)$ \\
\hline Control & 80 & $69^{\mathrm{a}}$ & 5.4 & 1463 \\
Flavophospholipol & 82 & $69^{\mathrm{a}}$ & 4.9 & 1410 \\
Probiotics & 79 & $58^{\mathrm{ab}}$ & 3.6 & 1333 \\
$0.25 \% \mathrm{HP}$ & 76 & $52^{\mathrm{b}}$ & 5.0 & 1096 \\
$0.50 \% \mathrm{HP}$ & 81 & $50^{\mathrm{b}}$ & 5.9 & 1593 \\
$0.75 \% \mathrm{HP}$ & 81 & $50^{\mathrm{b}}$ & 4.2 & 1413 \\
\hline SEM & 5.0 & 4.0 & 0.8 & 175.0 \\
P-value & 0.963 & 0.015 & 0.521 & 0.513 \\
\hline
\end{tabular}

Means with different subscripts in the same column differ significantly $(P<0.05)$; SEM: Standard error of means.

Table 11. Effect of treatment on antibody titers against Newcastle disease virus and avian influenza virus in broilers

\begin{tabular}{lcccc}
\hline \hline \multicolumn{1}{c}{ Treatments } & $\begin{array}{c}\text { Antibody response to } \\
\text { Newcastle vaccine } \\
(28 \text { days })\end{array}$ & $\begin{array}{c}\text { Antibody response to } \\
\text { Newcastle vaccine } \\
(42 \text { days })\end{array}$ & $\begin{array}{c}\text { Antibody response to } \\
\text { influenza vaccine } \\
(28 \text { days })\end{array}$ & $\begin{array}{c}\text { Antibody response to } \\
\text { influenza vaccine } \\
(42 \text { days })\end{array}$ \\
\hline Control & 4.0 & 2.0 & $1.0^{\mathrm{b}}$ & $0.3^{\mathrm{b}}$ \\
Flavophospholipol & 4.0 & 2.0 & $1.0^{\mathrm{ab}}$ & $1.3^{\mathrm{ab}}$ \\
Probiotics & 4.7 & 2.0 & $2.0^{\mathrm{a}}$ & $1.7^{\mathrm{a}}$ \\
$0.25 \%$ HP & 3.7 & 2.0 & $1.0^{\mathrm{ab}}$ & $1.0^{\mathrm{ab}}$ \\
$0.50 \%$ HP & 3.0 & 2.0 & $2.0^{\mathrm{ab}}$ & $0.7^{\mathrm{ab}}$ \\
$0.75 \%$ HP & 3.0 & 2.0 & 0.41 & $1.7^{\mathrm{a}}$ \\
\hline SEM & 0.72 & 0.32 & 0.284 & 0.45 \\
P-value & 0.541 & 0.656 & 0.021 \\
\hline
\end{tabular}

Means with different subscripts in the same column differ significantly $(P<0.05)$; SEM: Standard error of means.

production against SRBC, and IgM and IgG levels did not differ significantly among the groups, the increase in antiinfluenza antibody titer may have been accidental. In addition, determination of HI antibody titers, which involves a manual dilution step, is not precise. Kheiri et al. (2014) reported that the hogweed extract considerably enhanced broiler antibody titer against Newcastle disease virus. This could be because of the presence of flavonoids or furanocoumarins in $H$. persicum, which can increase humoral response by stimulating macrophages and beta-lymphocytes that are involved in antibody synthesis (Sharififar et al.,
2009). Furthermore, the hogweed extract may also exert a stimulatory effect on lymphocytes and accessory cell types (Vimal and Devaki 2004; Kheiri et al., 2014).

The Lactobacillus counts in the ileum of birds fed $0.5 \%$ or $0.75 \%$ HP were significantly higher than those observed after other treatments, whereas E. coli counts in all treatment groups were significantly lower than that in the control. This indicates that HP positively affects the gut microbiota and subsequently improves feed digestion and utilization.

In conclusion, addition of $0.50-0.75 \%$ HP to broiler diet over the entire rearing period improved weight gain and 
Table 12. Effect of treatment on antibody titers against SRBC, IgG, and IgM at day 28 and 42

\begin{tabular}{lcccccc}
\hline \hline \multicolumn{1}{c}{ Treatments } & $\begin{array}{c}\text { SRBC } \\
(28 \text { days })\end{array}$ & $\begin{array}{c}\text { IgG } \\
(28 \text { days })\end{array}$ & $\begin{array}{c}\text { IgM } \\
(28 \text { days })\end{array}$ & $\begin{array}{c}\text { SRBC } \\
\text { (42 days })\end{array}$ & $\begin{array}{c}\text { IgG } \\
\text { (42 days })\end{array}$ & $\begin{array}{c}\text { IgM } \\
(42 \text { days })\end{array}$ \\
\hline Control & 2.3 & $1.0^{\mathrm{b}}$ & 1.3 & 4.3 & 2.7 & 1.7 \\
Flavophospholipol & 4.0 & $1.3^{\mathrm{a}}$ & 1.7 & 5.0 & 3.0 & 1.7 \\
Probiotics & 4.7 & $2.3^{\mathrm{a}}$ & 2.7 & 6.0 & 3.3 & 2.7 \\
$0.25 \% \mathrm{HP}$ & 2.7 & $1.7^{\mathrm{a}}$ & 1.0 & 4.7 & 3.3 & 1.7 \\
$0.50 \% \mathrm{HP}$ & 4.0 & $1.3^{\mathrm{a}}$ & 1.7 & 5.0 & 3.3 & 1.3 \\
$0.75 \% \mathrm{HP}$ & 4.7 & $2.3^{\mathrm{a}}$ & 2.7 & 6.0 & 3.7 & 2.3 \\
\hline SEM & 1.00 & 0.71 & 0.53 & 0.73 & 0.72 & 0.33 \\
P-value & 0.586 & 0.024 & 0.265 & 0.531 & 0.964 & 0.194 \\
\hline
\end{tabular}

Means with different subscripts in the same column differ significantly $(P<0.05)$; SEM: Standard error of means.

Table 13. Effects of treatment on counts of $\boldsymbol{E}$. coli, coliform, lactobacilli, and total aerobic bacteria in intestinal digesta of 42-day-old broilers $(\log \mathrm{CFU} / \mathrm{g})$

\begin{tabular}{lcccc}
\hline \hline \multicolumn{1}{c}{ Treatments } & E. coli & Coliform bacteria & Lactobacilli & Total aerobic bacteria \\
\hline Control & $6.9^{\mathrm{a}}$ & 6.5 & $3.0^{\mathrm{c}}$ & 8.1 \\
Flavophospholipol & $5.3^{\mathrm{b}}$ & 8.0 & $4.5^{\mathrm{b}}$ & 8.6 \\
Probiotics & $4.3^{\mathrm{b}}$ & 7.9 & $5.5^{\mathrm{ab}}$ & 7.4 \\
$0.25 \% \mathrm{HP}$ & $4.1^{\mathrm{b}}$ & 7.6 & $4.8^{\mathrm{ab}}$ & 7.8 \\
$0.50 \% \mathrm{HP}$ & $4.8^{\mathrm{b}}$ & 6.3 & $5.7^{\mathrm{a}}$ & 7.4 \\
$0.75 \% \mathrm{HP}$ & $4.8^{\mathrm{b}}$ & 7.7 & $5.8^{\mathrm{a}}$ & 8.4 \\
\hline SEM & 0.41 & 0.52 & 0.34 & 0.22 \\
P-value & 0.002 & 0.912 & 0.001 & 0.781 \\
\hline
\end{tabular}

Means with different subscripts in the same column differ significantly $(P<0.05)$; SEM: Standard error of means.

decreased fat deposition due to improved glucose kinetics and the hypolipidemic property of HP, respectively.

\section{Conflict of Interest}

The authors declare no conflict of interest regarding the publication and dissemination of knowledge presented in this study.

\section{Acknowledgments}

Financial support by the Rasht Branch, Islamic Azad University, is gratefully acknowledged.

\section{References}

Asgarpanah J, Mehrabani GD, Ahmadi M, Ranjbar R and Ardebily MSA. Chemistry, pharmacology and medicinal properties of Heracleum persicum Desf. Ex Fischer: A review. Journal of Medicinal Plant Research, 6: 1813-1820. 2012.

Balevi T, Ucan U, Cokun B, Kurtolu V and Cetingül S. Effect of dietary probiotic on performance and humoral immune response in layer hens. British Poultry Science, 42: 456-461. 2001.

Barham D and Trinder P. An improved color reagent for the determination of blood glucose by the oxidase system analyst. The Analyst, 97: 142-145. 1972.

Dhama K, Latheef SK, Saminathan M, Abdul Samad H, Karthik K, Tiwari R, Khan RU, Alagawany M, Farag MR, Alam GM, Laudadio $\mathrm{V}$ and Tufarelli V. Multiple beneficial applications and modes of action of herbs in poultry health and production a review. International Journal of Pharmacology, 11: 152-176. 2015.

Hajhashemi V, Dashti G, Saberi S and Malekjamshidi P. The effect of hydroalcoholic extract and essential oil of Heracleum persicum on lipid profile in cholesterol-fed rabbits. Avicenna Journal of Phytomedicine, 4: 144. 2014.

Hasani R, Mehregan I, Larijani K, Nejadsattari T and Scalone R. Environmental Efficacy on Heracleum persicum Essential Oils. International Journal of Biological, Biomolecular, Agricultural, Food and Biotechnological Engineering, 10: 268-274. 2016.

Hashemi SR and Davoodi H. Phytogenics as new class of feed additive in poultry industry. Journal of Animal and Veterinary Advances, 9: 2295-2304. 2010.

Jahromi MF, Altaher YW, Shokryazdan P, Ebrahimi R, Ebrahimi M, Idrus Z, Goh YM, Tufarelli V and Liang JB. Dietary supplementation of a mixture of lactobacillus strains enhances performance of broiler chickens raised under heat stress conditions. International Journal of Biometeorology, 60: 10991110. 2016.

Khan RU, Naz S, Nikousefat Z, Tufarelli V and Laudadio V. Thymus vulgaris: alternative to antibiotics in poultry feed. World Poultry Science Journal, 68: 401-408. 2012a.

Khan RU, Naz S, Javdani M, Nikousefat Z, Selvaggi M, Tufarelli V and Laudadio V. The use of turmeric (Curcuma longa) in poultry feed. World Poultry Science Journal, 68: 97-103. 2012b.

Kheiri F, Rahimian Y and Rafiee A. Effect of Heracleum persicum 
extract on performance and some haematological parameters in broiler chicks. Research Opinions in Animal and Veterinary Sciences, 4: 522-525. 2014.

Nazemi A, Hashemi M, Khataminejad MR and Pourshamsian K. Antimicrobial activity of aqueous and methanol extracts of Heracoleum Persicum. Medical Science Journal of Islamic Azad Univesity-Tehran Medical Branch, 15: 91-94. 2005.

Phuwapraisirisan P, Surapinit S and Tip-pyang S. A novel furanocoumarin from Feroniella lucida exerts protective effect against lipid peroxidation. Phytotherapy Research, 20: 708710. 2006.

Sanjyal S and Sapkota S. Supplementation of broilers diet with different sources of growth promoters. Nepal Journal of Science and Technology, 12: 41-50. 2011.

Sayyah M, Moaied S and Kamalinejad M. Anticonvulsant activity of Heracleum persicum seed. Journal of Ethnopharmacology, 98: 209-211. 2005.

Schmid M and Von Forstner D. Laboratory Testing in Veterinary Medicine Diagnosis and Clinical Monitoring, pp. 253, Boehringer Mannheim GmbH, Mannheim, Germany. 1986.

Sefidkon F, Dabiri M and Mohammad N. Analysis of the oil of Heracleum persicum L. (leaves and flowers). Journal of Essential Oil Research, 16: 295-297. 2004.

Seidavi A, Dadashbeiki M, Alimohammadi-Saraei MH, van den Hoven R, Payan-Carreira R, Laudadio V and Tufarelli V. Effects of dietary inclusion level of a mixture of probiotic cultures and enzymes on broiler chickens immunity response. Environmental Science and Pollution Research, 24: 46374644. 2017.

Souri F, Farsam H, Sarkheil P and Ebadi F. Antioxidant activity of some furanocoumarins isolated from Heracleum persicum. Pharmaceutical Biology, 42: 396-399. 2004.

Shahrani M, Nabavizadeh F, Shirzad H, Yousefi H, Moradi M and Moghaddasi J. Effect of Heracleum persicum extract on acid and pepsin secretion level in both basic and stimulated conditions with pentagastrin in rat. Journal of Shahrekord Uuniversity of Medical Sciences, 7: 35-41. 2006.
Shamsi S, Seidavi AR, Rahati M and Nieto JAD. Edible mushroom powder (Agaricus bisporus) and flavophospholipol improve performance and blood parameters of broilers. Revista Colombiana de Ciencias Pecuarias, 28: 291-302. 2015a.

Shamsi S, Seidavi AR, Rahati M and Nieto JAD. Effect of mushroom powder and flavophospholipol oncarcass in broiler chickens. Revista Mexicana de Ciencias Pecuarias, 6: 469481. 2015b.

Sharififar F, Pournourmohammadi S and Arabnejad M. Immunomodulatory activity of aqueous extract of Heracleum persicum Desf. in mice. Iranian Journal of Pharmacological Research, 8: 287-292. 2009.

SPSS. SPSS Base 7.5 for Windows. SPSS, Chicago, IL. 1997.

Sweeney ME and Johnson RR. Ezetimibe: an update on the mechanism of action, pharmacokinetics and recent clinical trials. Expert Opinion on Drug Metabolism \& Toxicology, 3: 441450. 2007.

Torres-Rodriguez A, Sartor C, Higgins SE, Wolfenden AD, Bielke LR, Pixley CM, Sutton L, Tellez G and Hargis BM. Effect of Aspergillus meal prebiotic (Fermacto) on performance of broiler chickens in the starter phase and fed low protein diets. Poultry Science, 14: 665-669. 2005.

Trinder P. Determination of blood glucose using an oxidaseperoxidase system with a non-carcinogenic chromogen. Journal of Clinical Pathology, 22: 158-161. 1969.

Tufarelli V, Crovace AM, Rossi G and Laudadio V. Effect of a dietary probiotic blend on performance, blood characteristics, meat quality and faecal microbial shedding in growingfinishing pigs. South African Journal of Animal Science, 47: 875-882. 2017.

Vimal V and Devaki T. Linear furanocoumarin protects rat myocardium against lipid peroxidation and membrane damage during experimental myocardial injury. Biomedicine \& Pharmacotherapy, 58: 393-400. 2004.

Wallace RJ, Oleszek W, Franz C, Hahn I, Baser KHC, Mathe A and Teichmann K. Dietary plant bioactives for poultry health and productivity. British Poultry Science, 51: 461-487. 2010. 